\title{
Logic and the Development of Scientific Competencies in First-Year General Education
}

\author{
Mandana Sobhanzadeh ${ }^{1 *}$, Karim Dharamsi ${ }^{2}$, Nicholas Strzalkowski ${ }^{1}$, Peter Zizler ${ }^{3}$, Eric Roettger ${ }^{1}$ \\ ${ }^{1}$ Department of General Education, Mount Royal University, Calgary, Canada \\ ${ }^{2}$ Faculty of Arts and Sciences, St Mary's University, Calgary, Canada \\ ${ }^{3}$ Department of Mathematics and Computing, Mount Royal University, Calgary, Canada \\ Email: *msobhanzadeh@mtroyal.ca
}

How to cite this paper: Sobhanzadeh, M., Dharamsi, K., Strzalkowski, N., Zizler, P., \& Roettger, E. (2021). Logic and the Development of Scientific Competencies in First-Year General Education. Creative Education, 12, 2580-2593.

https://doi.org/10.4236/ce.2021.1211193

Received: September 12, 2021

Accepted: November 14, 2021

Published: November 17, 2021

Copyright (c) 2021 by author(s) and Scientific Research Publishing Inc. This work is licensed under the Creative Commons Attribution International License (CC BY 4.0).

http://creativecommons.org/licenses/by/4.0/

\begin{abstract}
Since 2008, Mount Royal University (MRU) has been committed to providing students with capacities for quantitative reasoning and the kind of literacy we have come to associate with the interpretation and assessment of scientific ideas shaping public discourse. After ten years, it was decided to revise the curriculum primarily responsible for supporting this mandate. A notable revision was the addition of a unit on logic in the course "GNED1101: Scientific and Mathematical Literacy for the Modern World", MRU's foundational course on quantitative reasoning. Logic was added to improve students' critical reasoning and ability to assess arguments, especially those made by practicing scientists. Interviews with students who have completed class activities and discussions about the modified curriculum show a positive impact of studying logic on their learning skills such as problem solving, writing and understanding scientific texts along with everyday life events. In this paper, we present the rationale behind this curriculum change, the importance of connecting the study of logic to the study of science in the first year of every degree program, and the share some activities that we use in our classrooms to emphasize the relationship between logic and science. We also present student views gathered through semi-structured interviews.
\end{abstract}

\section{Keywords}

Logic and Science, Teaching Logic to Science Students

\section{Introduction}

Logic is the formal study of the principles of correct reasoning. Year of research supports a long-held intuition that logic and critical thinking can improve stu- 
dent understanding of the concepts presented across a variety of disciplinary areas (Durand-Guerrier, 2003; Fitch, 2012; Hoyles \& Küchemann, 2002; Jenicek \& Hitchcock, 2004; Morou \& Kalospyros, 2011). Jenicek \& Hitchcock (2004) have suggested that:

our entire professional life is a wild world of arguments-meant in the sense of exchanges between people sharing information and giving reasons which form the bases, grounds, and warrants for their claims. Since logic and critical thinking is about rational uses of evidence, a valuable preparation for professional practice would naturally include learning the proper uses of evidence in daily practice and research.

In 2017, MRU's Department of General Education formed an institution-wide committee to revise GNED 1101, "Scientific and Mathematical Literacy for the Modern World" - a first year course offered to all degree students. The course is offered in multiple sections ( $>30$ of $\sim 40$ students each) taught by numerous math and/or science instructors. All instructors cover the same curricular content and a common final exam is delivered across all sections to provide a summative assessment of student learning. An introduction to logic is the first unit covered since the guiding presupposition is that subsequent units will exploit the intellectual competencies necessary for the kind of problem solving demanded by science. For instance, after teaching logic, students are introduced to scientific method-a procedural framework with which, at minimum, they assume some familiarity. Not without their own controversies, a methodological account is provided for the principle of falsifiability and forms of reasoning, including key distinctions between deductive and inductive judgments. These concepts are seeded as students develop scientific literacy and competencies to evaluate scientific claims.

In subsequent topics such as "Nuclear Energy and Radioactivity", students learn about seminal experiments leading to significant discoveries. They apply logic to critically assess the experiments and the justificatory inferences required to anchor such discoveries and demarcate between science and pseudoscience.

Here is an example of a class activity in which students use logic to evaluate the arguments about an experiment in physics:

Wolfgang Pauli and Enrico Fermi hypothesized the existence of a third particle in the products of beta decay in 1933. Since the energy of the electron in beta decay has a range of possible values, it means that a third very light particle must also be produced so that it carries the remainder of the available energy. Enrico Fermi coined the word neutrino for the 'little neutral one' (Tsokos, 2010). A group of MRU students performed an experiment in which a neutron at rest decayed and released a proton and an electron. They expected both the energy and momentum to stay the same before and after the nuclear decay (conservation of momentum and conservation of 
energy). They observed that energy and momentum before and after the nuclear decay are not the same and therefore suggested the presence of another particle with appropriate momentum and energy to balance the event (Neutrino).

Use truth tables to evaluate whether the following arguments about this experiment are valid or invalid.

Hypothetical Conditional: If the energy before and after the nuclear decay is not the same and the momentum before and after the nuclear decay is not the same, then there is a new particle involved in this event.

Disjunctive Statement: Energy is not the same before and after the nuclear decay or the momentum before and after the nuclear decay is not the same. Conclusion: Therefore, a new particle is involved in this nuclear decay.

p: Energy before and after the nuclear decay is the same.

q: Momentum before and after the nuclear decay is the same.

$\mathrm{r}$ : There is a new particle involved in this event.

$\left(\sim \mathrm{p}^{\wedge} \sim \mathrm{q}\right) \rightarrow$ r Premise 1

$\sim \mathrm{p} \vee \sim \mathrm{q}$ Premise 2

r Conclusion

\begin{tabular}{cccccccccc}
\hline $\mathrm{p}$ & $\mathrm{q}$ & $\mathrm{r}$ & $\sim \mathrm{p}$ & $\sim \mathrm{q} \sim \mathrm{p} \wedge \sim \mathrm{q}$ & $\begin{array}{c}(\sim \mathrm{p} \wedge \sim \mathrm{q}) \rightarrow \mathrm{r} \\
\text { Premise } 1\end{array}$ & $\begin{array}{c}\sim \mathrm{p} \vee \sim \mathrm{q} \\
\text { Premise } 2\end{array}$ & $\begin{array}{c}\text { Premise } 1 \wedge \\
\text { Premise } 2\end{array}$ & $\begin{array}{c}\text { [Premise } \wedge \\
\text { Premise2] } \\
\text { Conclusion }\end{array}$ \\
\hline $\mathrm{T}$ & $\mathrm{T}$ & $\mathrm{T}$ & $\mathrm{F}$ & $\mathrm{F}$ & $\mathrm{F}$ & $\mathrm{T}$ & $\mathrm{F}$ & $\mathrm{F}$ & $\mathrm{T}$ \\
$\mathrm{T}$ & $\mathrm{T}$ & $\mathrm{F}$ & $\mathrm{F}$ & $\mathrm{F}$ & $\mathrm{F}$ & $\mathrm{T}$ & $\mathrm{F}$ & $\mathrm{F}$ & $\mathrm{T}$ \\
$\mathrm{T}$ & $\mathrm{F}$ & $\mathrm{T}$ & $\mathrm{F}$ & $\mathrm{T}$ & $\mathrm{F}$ & $\mathrm{T}$ & $\mathrm{T}$ & $\mathrm{T}$ & $\mathrm{T}$ \\
$\mathrm{T}$ & $\mathrm{F}$ & $\mathrm{F}$ & $\mathrm{F}$ & $\mathrm{T}$ & $\mathrm{F}$ & $\mathrm{T}$ & $\mathrm{T}$ & $\mathrm{T}$ & $\mathrm{F}$ \\
$\mathrm{F}$ & $\mathrm{T}$ & $\mathrm{T}$ & $\mathrm{T}$ & $\mathrm{F}$ & $\mathrm{F}$ & $\mathrm{T}$ & $\mathrm{T}$ & $\mathrm{T}$ & $\mathrm{T}$ \\
$\mathrm{F}$ & $\mathrm{T}$ & $\mathrm{F}$ & $\mathrm{T}$ & $\mathrm{F}$ & $\mathrm{F}$ & $\mathrm{T}$ & $\mathrm{T}$ & $\mathrm{T}$ & $\mathrm{F}$ \\
$\mathrm{F}$ & $\mathrm{F}$ & $\mathrm{T}$ & $\mathrm{T}$ & $\mathrm{T}$ & $\mathrm{T}$ & $\mathrm{T}$ & $\mathrm{T}$ & $\mathrm{T}$ & $\mathrm{T}$ \\
$\mathrm{F}$ & $\mathrm{F}$ & $\mathrm{F}$ & $\mathrm{T}$ & $\mathrm{T}$ & $\mathrm{T}$ & $\mathrm{F}$ & $\mathrm{T}$ & $\mathrm{F}$ & $\mathrm{T}$ \\
\hline
\end{tabular}

The argument is not a tautology (true in all cases) and is therefore invalid.

This example highlights the importance of using logical inference in assessing the conceptual design of scientific experiments-and also in establishing the kind of reasoning one is exploiting to better understand the relevant relation- 
ships between phenomena being studied. Like induction, this experiment involves observations. It does not however establish a general rule. Rather, it attempts to determine through a form of abductive inference a relationship between a cause and an effect.

One of the authors (MS) of this paper used to be a physics laboratory instructor. She noticed that it was common for students' "discussion and conclusion" sections of lab reports to not be logically valid. For example, one student used a conditional statement instead of a biconditional statement and the conclusion contained the inverse fallacy: if the net force acting on the object is zero then acceleration is zero. Net force is not zero therefore the object experienced an accelerated motion.

$\mathrm{p}$ : Net force is zero.

q: Acceleration is zero.

$\mathrm{p} \rightarrow \mathrm{q}$ Premise 1

$\sim$ p Premise 2

$\sim \mathrm{q}$ Conclusion

This argument is invalid (fallacy of inverse).

Further, she found that most students in physics labs were not familiar with logical relations, sometimes confusing "converse" and "inverse" conditionals in their reports.

For instance, a student in the Classical Physics I lab (PHYS1201) in MRU, argued that when an object is stationary, then its acceleration is zero $(p \rightarrow q$, where $\mathrm{p}$ : object is stationary, and q: acceleration is zero). Then he concluded that if the object is not stationary then the acceleration is not zero $(\sim p \rightarrow \sim q$, which is the inverse and is not equivalent to $\mathrm{p} \rightarrow \mathrm{q}$ ). The lab instructor (MS) showed him an example of an object moving with constant velocity and zero acceleration and explained that $\mathrm{p} \rightarrow \mathrm{q}$ and $\sim \mathrm{p} \rightarrow \sim \mathrm{q}$ are not equivalent. He argued that he did not mean that "if the acceleration is zero then the object is stationary" ( $q \rightarrow \mathrm{p}$, which is the converse). The lab instructor (MS) explained that inverse $(\sim p \rightarrow \sim q)$ and converse $(q \rightarrow p)$ are equivalent and provided an explanation of the logic of conditional, inverse, converse and contrapositive with examples related to the lab topic to clarify the mistakes that some students had made in their lab reports.

As others have indicated, examples of incorrect and incomplete explanations from scientists occur both in laboratory experiments and in other authentic learning environments (Feldon et al., 2010). Authentic learning environment is a pedagogical approach that situates learning tasks in the context of future use. It allows for the construction of meaning grounded in real-life situations and the learners own personal experience (Herrington, Reeves, \& Oliver, 2014).

\section{The Course}

GNED1101 is a 13-week multi-section course with around 1400 students, the majority in their first or freshman year. The course meets three lecture hours per 
week. Its primary aim is to enhance a student's capacity to understand core mathematical concepts and their intersection with science and technology-in the lived experience of their daily life. Hence the curriculum (ideally) helps students develop and apply critical, mathematical, and scientific reasoning skills through the examination of issues drawn from the real world and current events. The emphasis of this course is to encourage an understanding of how mathematics and science are connected and to encourage students to use quantitative and scientific methods to think about the things they encounter in the press, through politics, industry, and discussions in the public square.

The topics covered include:

1) Logic

2) Scientific method

3) Evaluating and Assessment of information,

4) Theory-change

5) Examining natural disasters (earthquakes),

6) Number system and calculations

7) Personal finance with focus on exponential growth

8) Conventional fossil fuel vs. nuclear energy

9) Understanding radioactivity and doing exponential decay calculations

10) Statistics

11) Prevalence and spread of infectious disease.

The textbook used in GNED 1101 is Thinking Mathematically (Blitzer \& Miller, 2011). There is also an online book written by a group of MRU faculty members (Understanding Our Physical World: How Numeracy and Scientific Thinking Build Knowledge) used in this course. The grade is based on $10 \%$ class activities, $60 \%$ assessments (quizzes and assignments) and 30\% final exam. The course learning outcomes are provided in Appendix A.

\section{Logic in Science}

Walter Monroe Fitch (2012) in The Three Failures of Creationism: Logic, Rhetoric, and Science shows the usefulness of logic in addressing scientific questions. He explains how logic and the scientific method are employed in studying evolution.

There can be confusion about what counts as science since its methods can, at a general level, be consistently applied to astrology and astrophysics, homeopathy, and vaccine research. For instance, both astrology and astronomy depend on "observation" and "observable phenomena". The astrologist and the astronomer both seek patterns and aim to identify causal relationships and their consequences by virtue of those patterns. Yet, there is an important difference between the astrologer and the astronomer. Sometimes those differences are accepted, but not explained. Whether it is the principle of falsifiability that helps us confidentially differentiate the astrologer from the astronomer or whether it is a misguided attempt to formulate a strict law where one is absent, the debate 
about what is and what is not a science seems to ride on both the kind of question we are asking and the kind of evidence we accept to justify our inferences.

Fitch (2012) believes that one of the challenges towards a student's understanding of the nature of science is the unfamiliarity with the logic of scientific reasoning. He therefore offers a study of basic deductive and inductive logic, including an explanation of the fallacies and rhetorical devices that creationists frequently employ. For example, he explains the fallacy of equivocation using a syllogism based on creationists' persistent misunderstanding of the term theory. Equivocation results from multiple uses and shifts in meaning of a particular word or expression in a single argument. Ambiguity results when a phrase or term with two or more distinct meanings is used to justify a conclusion. Since equivocation is not a grammatical error, it is often thought to be intentionally misleading, having an interlocutor come to an erroneous conclusion. The syllogism has a long and esteemed history in its categorical form. It is a type of reasoning in which a conclusion is drawn (whether validly or not) from two given or assumed premises, each of which shares a term with the conclusion and shares a common or middle term not present in the conclusion (e.g., all people who arrive late cannot perform. All people who cannot perform are ineligible for scholarship. Therefore, all people who arrive late are ineligible for scholarships) (Blitzer \& Miller, 2011). Through studying examples of correct and incorrect logical reasoning students can more fully understand the nature of science. Most standard logic textbooks typically illustrate this fallacy and syllogism using trivial examples. Fitch (2012) demonstrates the importance of this fallacy by showing the two very different arguments-one invalid and one valid-that result, respectively, from defining theory as "only a guess," as creationists do, and defining it scientifically as "a well-supported explanation of many observations" (pp. 10-12):

Premise 1: Evolution is a theory $(\mathrm{a}=\mathrm{b})$.

Premise 2: A theory is only a guess $(b=c)$.

Conclusion: Therefore, the theory of evolution is only a guess $(c=a)$.

This argument presents students with an interesting challenge. The syllogism is valid. Validity is only a formal criterion asking whether the form of the argument is syllogistic; it seems to retain transitivity. However, this argument is not sound. While it follows the formal structure of a syllogism, premises 1 and 2 equivocate on the meaning of 'theory' and come, therefore, to a misleading conclusion.

Premise 1: Evolution is a theory $(a=b)$.

Premise 2: A theory is only a guess $\left(b^{\star}=c\right)$.

Premise 3: Therefore, the theory of evolution is only a guess $(?=a)$.

Validity and soundness present a subtle difference in the kind of categorical syllogism used by Fitch. And students may challenge the truth of any premise but fail to grasp that validity is necessary but not a sufficient condition for truth. Note that in the second example $b$ and $b^{*}$ are not synonymous even though they both refer to "theory". 
A sound argument that does not equivocate on "evolution"-and does establish a transitive relation between its terms is:

Premise 1: Evolution is a theory $(a=b)$.

Premise 2: A theory is a well-supported explanation of many observations $(b=$ c).

Conclusion: Therefore, evolution is a well-supported explanation of many observations $(c=a)$.

Here $b$ in premise 1 retains its meaning in premise 2. This form of the argument is both valid and sound since it follows the form of the syllogism and its premises are true. Of course, truth here still belongs to the syllogism. Even if we establish that the conclusion is true, we might be challenged to answer, true of what? How do we know, even if we avoid equivocation on 'theory' that the truth of the argument is not merely analytic-forma?

In GNED1101, the "Scientific Method" is discussed after the unit on "Logic". We use similar examples to explain the definition of theory and point out the importance of logic in scientific reasoning. Our aim is to draw a line between the deductive form of reasoning used in Fitch's example and the force of inductive reasoning, core to the justificatory power of scientific method.

Students tend to memorize and mimic language, because they believe that linguistic competency is sufficient to demonstrate knowledge acquisition and comprehension (Arons \& Miner, 1990; Eger, 1993; Packer, 2010; Sobhanzadeh, 2015). Of course, students have the right intuitions even if their execution is misguided. They might be assuming as language users and students attempting to grasp complex ideas that their statements are true under certain conditions and that mimicking the form of true statements is tantamount to mimicking the comprehension of when conditions apply to render such statements true. In other words, one reason students memorize the scientific terms and definitions without thinking about their meanings and connections are that they are not familiar with the language of science and the application of logic in science (Arons \& Miner, 1990; Eger, 1992; Christiansen \& Kirby, 2003). However, they are familiar with how statements about the world are true under certain conditions-given their familiarity with their own language and its meanings. Scientific statements mimic natural language and so also mimic an assumed ready-made relationship between statement and fact, meaning and world. While this is outside the scope of this current study, we think it is important to signal the ingrained realist assumption the guides much of scientific inquiry, namely, that the world is 'real', and our true statements align accurately with the facts of the world. Since 'truth' is to logic what beauty is to art, it is not surprising that scientific method and reasoning covets truth over mere possibility (Fitch, 2012).

While covering "logic" in GNED1101, one might ask students to discuss the following question with an aim to understand the application of contrapositive in science and the difference between conditional and biconditional statements.

Newton's first law tells us that an object in motion subject to no net force will 
continue to move in a straight line forever. Similarly, an object at rest subject to no net force will remain at rest forever.

This means that if $\boldsymbol{F}_{\text {net }}=0$, then $\boldsymbol{a}=0$ (uniform motion).

a) Write the following statement out using logic notation:

If the motion is non-uniform then there must be a net force acting on the object.

b) Explain in words what the following statement means:

$$
\sum \boldsymbol{F}=0 \leftrightarrow \mathrm{d} \boldsymbol{v} / \mathrm{d} t=0
$$

Part a. shows the importance of contrapositive arguments in science.

$\mathrm{p}$ : There is an object in motion or at rest subject to no forces.

$\mathrm{q}$ : acceleration is zero (uniform motion).

$\mathrm{p} \rightarrow \mathrm{q}$ If $\boldsymbol{F}_{\text {net }}=0$, then $\boldsymbol{a}=0$ (uniform motion)

$\sim \mathrm{q}$ Motion is non-uniform (acceleration is not zero).

$\sim p$ Net force is not zero.

Part b. shows that Newton's first law is a biconditional statement: motion is non-uniform if and only if there is a net force acting on the object.

\section{Student Interviews}

We conducted semi-structured student interviews to study the importance of group size in completing class activities in GNED 1101. A total of six first year students were interviewed from the fall 2019, winter 2020 and fall 2021 semesters. Two class activities were conducted from the logic unit. Here we share the parts of the interviews about what students thought about the importance of logic to their study of scientific concepts. The interview questions relevant to this paper are found in Appendix B. The interviews helped us address a number of questions about the addition of logic to the GNED1101 curriculum. They helped us to gather information about how the logic unit is viewed by this sample of students. Most importantly, they also allow us to see if students understand the importance of logic in science. Any hermeneutic analysis attempts to interpret meanings and their relations. Interviewing is an important source of the kind of data we require to establish an assessment of student understanding. Interviews allow us access what students are thinking- "what is in and on someone else's mind" (Patton, 1982). Interviews permit a lot of detail to be collected that would not normally be easily obtained by other research designs. In this research work, we followed the coding strategies presented by grounded theory approach to analyze the interview transcripts. Coding in grounded theory involves the twin practices of abstraction and generalization. Abstraction practice involves separating a whole into elements that are distinct from one another. These distinct elements shape their original context. Generalizing practice involves finding what is common or repeated among these elements (Charmaz \& Belgrave, 2007; Corbin \& Strauss, 2008; Packer, 2010). After coding the entire text, we made a list of all code words and then grouped similar codes and found the redundant 
codes to reduce a list of codes to a smaller, more manageable number. We used the NVivo software to explore the trustworthiness of the emerged codes and conceptual categories.

The first interviewee was a student who intended to study international business at MRU. We refer to him as, Ahmed. We refer to the second and third students, who were chemistry students as Bill and Catherine, respectively. The fourth student wished to enter the biology major beginning in his second-year and we call him, Dan. We refer to the fifth student as Bob (he planned to get a Bachelor of Arts, criminal justice degree), and the sixth student as Zara (she was studying nursing).

The points mentioned by all interviewees explaining their perspectives on logic in GNED1101 can be classified into two broad categories: first, the influence of logic on learning outcomes listed below, and second the kind of reflective and analytical capacities to reason logic seems to enhance, even in relation to everyday life events:

1) Students demonstrate better use of scientific concepts on written assignments. Logic helps students in writing scientific texts such as lab reports.

2) Logic helps students make better understand scientific concepts.

3) Logic improves problem solving skills.

All interviewees acknowledged that logic not only has helped them in writing lab reports in science but also in understanding the materials presented in science textbooks. The language of science is a language that scientists use to talk about the natural world (Eger, 1993). Since meanings are normally constitutive of their uses, for the uninitiated student (or member of the public) scientific terms can be unmoored abstractions. Memorizing concepts, detached from their particular uses in the understanding of nature, presents significant pedagogical challenges for students and faculty. Of course, lab and field experiences can ameliorate student discomfort with scientific concepts; their uses would make sense and students would presumably apply concepts under appropriate correctness conditions. However, "in-world" experiences are not enough to establish relations between our practices. Eger (1993) rightly believes that memorizing the terms and definitions without thinking about the meaning and understanding the concepts is the most important problem for science education. This suggests that 'in-world' experiences are important-and no doubt they are. Problems of meaning arise because students learn concepts in the vacuum of textbooks and classrooms. However, meanings also have relations. While our practices can establish the conditions under which the concept is correctly used, such practices in themselves cannot establish either the validity or soundness of our reasoning. Learning logic can help address a conceptual gap between concept use and consistency in science.

The following points mentioned by interviewees are related to the reasoning influences of logic on everyday life events:

1) Logic integrates awareness and encourages one to be more critical about 
the world events around.

2) It helps students make better arguments in different situations of everyday life.

3) It improves critical thinking, comparison, reasoning, and explaining about various world events around.

Notice that these three capacities assume a relationship between logical inference and scientific content. Logic is silent on what kind of content a student reasons about. Rather, logic provides a formal guide to assess our reasoning. All interviewees explained that learning logic in GNED1101 helped them to be more critical about what they see and hear in everyday life. By this we assume that the capacities to better evaluate one's inferences helps render consistency to one's judgements about the trials of everyday life. Given this, the last two points are highly related to each other. Logic improves critical thinking and reasoning and as a result helps students make better arguments in different situations from friendly conversations to formal debates and writing articles and essays.

Some statements made by Interviewees about the influence of logic on learning skills (problem solving, writing and understanding scientific texts) and everyday life events are presented in Table 1. Eysink et al., (2011) state that reasoning occurs in all sciences and in all possible contexts. This is an unsurprising claim since as language users living out our lives in linguistic communities, we are familiar with having to justify our beliefs and provide reasons for why we think something is the case. Logic can render some consistency to our reasoning in many of these everyday situations. Of course, formalized rules about reasoning are silent on specific content; the same rules apply in every situation under which appropriate conditions apply for the relevant rule. This makes logic abstract and general and, in some cases, formalizable. Introducing students to formal logic, the first order predicate calculus for example, can help demonstrate the structural clarity logic can provide to natural language. In everyday life, people can develop naïve notions about logical reasoning. Of course, knowing the rules does not in itself make you a better reasoner and not all good reasoning involves explicit understanding of logic. We have been in the academy long enough to not assume this. In the context of scientific reasoning, when our ideas about the world are vetted by way of experiment and explicit methodological decisions about research design, logic can aid in consistency, in helping us understand the limitations of our concepts and their meanings. It can also help us identify cases of equivocation and other fallacious forms of reasoning. Perhaps most importantly, if the learners develop certain ideas, it is difficult to change their minds and to convince them they should replace their prejudices or preferences with the new ideas that contradict their pre-existing ideas. The neutrality of sound arguments on our desires and particular interests may be the greatest virtue of logic's essential place in scientific thinking.

Teachers of logic are often confronted with the problem of how to teach students to solve problems and to translate natural language statements into formal 
Table 1. Some statements made by Interviewees about the influence of logic on learning skills and everyday life.

Interviewee Statements

Ahmed

"First, I saw logic as applying meaningless rules. I did not see any relations between the logic rules and First-year Bachelor of Business real-life meaning. I wasn't [sic] able to apply logic rules to everyday phenomena before being exposed to Administration (BBA) student class discussions and worksheets. In this class, I learned to go step by step to solve a problem. My solving method needs to be valid. Well, I can use these skills in various situations. Problem-solving is a universal job skill that applies to any position and every workplace. Your method of solving problems need to be valid... Let me share one of my experiences with you. Here on campus, you hear contradicting opinions about the same topic from your professors. First, I was very confused and had a difficult time processing all these contradictions. Now I can use logic to evaluate what I hear. Before, I had no idea what to do when faced by conflicting advice from experts. Now I know the tools to evaluate what I see and hear. When I read the news, I have more confidence to evaluate what I read without being an expert myself ... I have a motorcycle and I was reading a CBC article about the detectors capturing noisy vehicles and motorcycles in Edmonton. There were many statements made by Ben Henderson about this issue in that article. The article pointed out a project about noise monitoring in Edmonton. The statements made by Henderson caught my attention since they were full of logical fallacies. In this article he talks about combating noise by banning all motorcycles from core neighborhoods in Edmonton or he says we will continue the project of detecting noise for another summer to tell us what we already know. Well, isn't [sic] this the fallacy of begging the question, when the premise of an argument assumes a conclusion of its own in order to justify the final conclusion? I was able to criticize this article using what I learned in this class. Without knowing about logic, I wasn't [sic] able to make good arguments to question this article."

Bill

First-year chemistry student

Catherine

First-year chemistry student

Dan

First-year science student
“Logic helps me in assessing and upgrading my ability to judge well. We don't [sic] take enough time for logical thinking, problem-solving, and reasoning skills in the other classrooms. Actually, I am more careful in writing essays and lab reports now that I know logic. In a chemistry lab for example, I could say that if this sample contains sulfuric acid, then it will turn blue litmus paper red. The blue litmus paper turned red. Therefore, there is sulfuric acid in this sample. Nobody would blame me for saying this in my lab report, but now I know that this argument is not valid. I am very careful now when I write a lab report. Now that I know logic, the textbooks make more sense ... well, I go step by step to solve a problem. I make sure that every step makes sense, and the problem-solving method is consistent with logical rules."

"Logical thinking skills are important to our success both in and out of the classroom. Worksheets and class discussion on logic helped me develop an essential problem-solving skill for math reasoning and real-life experiences. logic helps me in math and solving problems in science because logical thinking is sequential, I think. Mandy [Catherine's course instructor] wrote down four steps to evaluate an argument and I can use these steps in solving problems. I learned to design sequential methods to solve a problem and my methods must be valid logically. To think logically about something means to think about it in steps. Math is a sequential process, I think. When you know logic, you can analyze a situation, understand the sequence, and ask yourself what comes next. Implementing logical thinking helps you to be rational, logical problem solvers, helps you see the world from many different angles."

"When we started the logic topic, I had no clue how important the topic is until we worked on the class activities. In class activities I saw the application of logic in writing lab reports, evaluating people's statements, evaluating articles, news, scientific papers, and you know, almost everything. What I see in my textbooks, are clear to me now. I want to become a scientist and logic has helped me answer many questions that I had about science, theory, and scientific method. I learned that science is not just empirical. You can't [sic] just simply collect and analyze data if you want to predict and explain how the 
Bob

First-year criminal justice student

Zara

First-year nursing student universe works. I think most of us have had the experience of explaining a scientific phenomenon and hearing some people saying that it is just a theory. Well, just a theory! I was talking to a friend last year about global warming and she told me it's just a theory. Theory is a misunderstood term used by many people. I myself misunderstood this scientific term when I was in high school. Class activities and discussions in this class improved my scientific knowledge ... For example, if you ask what the sky color will be tomorrow, every person can predict that the sky will be blue. They have a lifetime of empirical that lets them make that prediction, but few can explain why the sky is blue. That needs an explanation, a theory. A theory to explain this must be logically consistent with other related theories. The theory itself is assessed in a variety of ways; one is internal logical consistency. Saying something is just a theory means we have no knowledge of the scientific method and logic. In this course, we learned that the theory should generate hypotheses that are logically derived from the theory's premises and propositions. The hypotheses must be open to testing. A logical argument is needed to assess the quality and effectiveness of the testing processes, you know the methodology. Logic is central to every phase of the scientific method ... When you are studying and solving a problem in science, you need to be careful about the problem-solving method that you design, just ask yourself if your method is consistent with logic rules. A is equal to B, B is equal to $\mathrm{C}$, can I conclude that $\mathrm{A}$ is equal to $\mathrm{C}$ ?"

"For me, logic was one of the harder units in this course. But there is an applicable aspect of it, I had enjoyed it and felt I was able to learn a couple of useful skills moving forward. As people, everything is a negotiation, and we will have lots of conversations whether with an employer, co-worker, or a partner. Being able to both interpret the arguments that others make to you and being able to make your position very logically sound will strengthen any claims that you may make. One of the biggest elements of logic is being able to detect logical fallacies. Looking at sales jobs or work environments people will try and manipulate you for their own best interest in a variety of ways, but if you possess the ability to breakdown the argument or point being presented then it can change how you deal with it. It is very important to understand the topic of logic and be able to implement it into your conversations as well as being able to identify those claims or arguments we are faced with in everyday life so you will not be manipulated into doing things and will have more truthful interactions ... I also learned how to solve problems in my other courses. How to write down the information given and then design a valid methodology to come up with a reasonable conclusion ... Learning about quantified statements and their negation, along with conditional and biconditional statements have given me a better understanding of the effect a statement can have. This understanding has been extremely beneficial within completing my essays in other courses, as it has allowed me to have a better understanding of the effect my statements have. The composition and effect of a sentence can be greatly altered based on the chosen words and their corresponding order. To apply the topic of conditional statements, which are if-then statements, if I were to confuse the order of an argument in my essay, it could have the opposite effect than which is desired. I must comprehend the $\mathrm{p} \rightarrow \mathrm{q}$ aspects of my argument and determine if they make sense within their sequential order. If I find that one of my statements is incorrectly ordered, therefore making it invalid, I can use the teachings from the topic of logic to help me correct my errors to ensure my essay remains valid. I believe logic will strengthen my communication in my essays and writing assignments and lab reports."

"Logic is something that is part of everyday life. If one can construct good arguments, and train themselves to spot bad arguments, they will be better prepared for success in the majority of work environments as well as everyday life ... Logic allows a person valuable skills to use in their everyday life. This skill allows a person to know if an argument is valid or weak and draw inferences that are useful in the situation. By using logic, we can make the best possible educated decision as we are steered in the direction of the truth and away from falsehoods presented ... A person can become a critical reader, listener, and thinker by becoming more familiar with logic and truth tables. You can't [sic] always believe 


\section{Continued}

everything you hear, you need to be able to think critically and logically to understand the information to know if it is reliable versus what is just erroneous information to confuse the decision ... Personally, I believe logic is helpful and important because it can help with other classes, like planning and writing an essay or an assignment or even solving a problem. When I read my chemistry textbook, I understand the sentences because I know logic. When I write a lab report, I know how to use conditional or biconditional statements and I avoid inverse and converse fallacies. I have learned to organize the premises to validate my arguments when I write an essay or provide a lab report. Logic has helped me in other courses. Writing an essay, you can use logic to write certain statements in an equivalent way. Logic has taught me how to write statements in an equivalent form, so you are not repeating yourself in an essay ... Because of logic, I became more aware of any statements that I daily encounter or the statements that I write in my essays and lab reports. I recently have written a logical persuasive essay for my GNED 1401 class, and I am required to use strong evidence to back up my reasons and statements for them to be valid. When discussing a controversial topic, gaining this valuable knowledge about logic during my first semester at university is helping me to construct better arguments myself, which enhances my influence on others if I am trying to make a point. I can evaluate what I hear, what I read, what I see because I know logic.”

statements. By incrementally increasing the complexity of problems and relating them to both real-world phenomena and our theories, teachers can make learning logic interesting and show students the application of logic in various contexts. As can be seen in Table 1, most interviewees found logic confusing at the beginning of the semester and when they were exposed to the class discussions and the class activities about the application of logic in everyday life, they started realizing the importance of logic in various contexts.

\section{Conclusion}

In this paper, we discussed the importance of connecting the study of logic to the study of science in the first year of a general education program. The interviews with students show that one of the most important parts of teaching logic is to make connections among logic, its application in everyday life and the application of logic in various disciplines. The interviewees acknowledged the positive impact of studying logic on their learning skills such as problem solving, writing and understanding scientific texts along with everyday life events. It is very important to provide examples related to everyday life while teaching logic unit. Creating worksheets and class activities to discuss the fallacies and validating the arguments related to everyday life, science labs and various disciplines are very helpful in teaching logic. The results of this study show the importance of logic in science laboratories, where students need to prepare a lab report as well as reading science textbooks, where students need to make sense of the scientific arguments. Logic would help students make arguments that are logically valid in the lab reports and make sense of the materials presented in the science textbooks such as understanding the differences between conditional and biconditional scientific statements. 


\section{Conflicts of Interest}

The authors declare no conflicts of interest regarding the publication of this paper.

\section{References}

Arons, A. B., \& Miner, T. D. (1990). A Guide to Introductory Physics Teaching. The Physics Teacher, 28, 426-426. https://doi.org/10.1119/1.2343097

Blitzer, R., \& Miller, D. S. (2011). Thinking Mathematically. Prentice Hall.

Charmaz, K., \& Belgrave, L. L. (2007). Grounded Theory. In The Blackwell Encyclopedia of Sociology (pp. 2023-2027). Blackwell Publishing Ltd. https://doi.org/10.1002/9781405165518.wbeosg070

Christiansen, M. H., \& Kirby, S. E. (2003). Language Evolution. Oxford University Press. https://doi.org/10.1093/acprof:oso/9780199244843.001.0001

Corbin, J., \& Strauss, A. (2008). Basics of Qualitative Research: Techniques and Procedures for Developing Grounded Theory. SAGE Publishing. https://doi.org/10.4135/9781452230153

Durand-Guerrier, V. (2003). Which Notion of Implication Is the Right One? From Logical Considerations to a Didactic Perspective. Educational Studies in Mathematics, 53, 5-34. https://doi.org/10.1023/A:1024661004375

Eger, M. (1993). Hermeneutics as an Approach to Science: Part II. Science \& Education, 2, 303-328. https://doi.org/10.1007/BF00488169

Eysink, T. H., Dijkstra, S., \& Kuper, J. (2001). Cognitive Processes in Solving Variants of Computer-Based Problems Used in Logic Teaching. Computers in Human Behavior, 17, 1-19. https://doi.org/10.1016/S0747-5632(00)00038-8

Feldon, D. F., Timmerman, B. C., Stowe, K. A., \& Showman, R. (2010). Translating Expertise into Effective Instruction: The Impacts of Cognitive Task Analysis (CTA) on Lab Report Quality and Student Retention in the Biological Sciences. Journal of Research in Science Teaching, 47, 1165-1185. https://doi.org/10.1002/tea.20382

Fitch, W. M. (2012). The Three Failures of Creationism: Logic, Rhetoric, and Science. University of California Press. https://doi.org/10.1525/9780520951662

Herrington, J., Reeves, T. C., \& Oliver, R. (2014). Authentic Learning Environments. In Handbook of Research on Educational Communications and Technology (pp. 401-412). Springer. https://doi.org/10.1007/978-1-4614-3185-5 32

Hoyles, C., \& Küchemann, D. (2002). Students' Understandings of Logical Implication. Educational Studies in Mathematics, 51, 193-223. https://doi.org/10.1023/A:1023629608614

Jenicek, M., \& Hitchcock, D. L. (2004). Evidence-Based Practice: Logic and Critical Thinking in Medicine. AMA Press.

Morou, A., \& Kalospyros, N. (2011). The Role of Logic in Teaching, Learning and Analyzing Proof. In Congress of the European Society for Research in Mathematics Education (Vol. 7, pp. 1-9).

Packer, M. (2010). The Science of Qualitative Research. Cambridge University Press. https://doi.org/10.1017/CBO9780511779947

Patton, M. Q. (1982). Qualitative Methods and Approaches: What Are They? New Directions for Institutional Research, 1982, 3-15. https://doi.org/10.1002/ir.37019823403

Sobhanzadeh, M. (2015). Implementing Reflective Writing in Combination with Labatorials.

Tsokos, K. A. (2010). Physics for the IB Diploma Full Colour. Cambridge University Press. https://doi.org/10.1017/CBO9780511863011 